\title{
The Role of Weather on Investors' Monday Irrationality: Insights from Malaysia
}

\author{
Rayenda Brahmana', Chee Wooi Hooy'2, Zamri Ahmad²
}

ABSTRACT Evidence supporting the weekend effect, also known as Monday Irrationality, has shown that con-
ventional finance is unable to follow a rational behavior assumption. Many scholars have proposed
a behavioral approach to explain this phenomenon; however, few studies have investigated this ef-
fect empirically. Interestingly, literature on weather patterns and the preliminary results of our study
have identified a particular weather cycle that occurs on Mondays, when the temperature in Malay-
sia is higher compared with other days. Therefore, this paper aims to investigate the role of weather
on investors'Monday irrationality. By analyzing the market index and size-based portfolio formation
model from 1999 to 2010, this research study found that the weather influenced investors' mood,
causing anomalous conditions in the market. Our findings conclude that the mood of investors
plays an important role on investment decisions and the resulting Monday irrationality of investors.

KEY WORDS: weather; monday irrationality; psychological finance; malaysian stock market

JEL Classification:

D03; G12; G14

${ }^{1}$ Universiti Malaysia Sarawak - Faculty of Economy and Business Kota Samarahan, Malaysia
${ }^{2}$ Universiti Sains Malaysia - School of Management Penang, Malaysia

\section{Introduction}

To elucidate the mechanisms behind investor irrationality Monday irrationality phenomenon, one of several market anomalies, many scholars have proposed a behavioral approach (i.e., Brahmana, Hooy, \& Ahmad, 2012a; Chin \& Abdullah, 2013; Goetzmann \& Zhu, 2005; Kudryavtsev, Cohen, \& Hon-Sir, 2013; Ritter, 1988). However, it is rare to find research studies that empirically test the association between these anomalies and human behavior. Monday irrationality, popularly referred to as the Monday effect, is a phenomenon that has been largely unsolved. There is

Correspondence concerning this article should be addressed to: Rayenda Brahmana, Universiti Sains Malaysia - School of Management Fellow/GA Room, School of Management, USM Minden Penang 11800, Malaysia. E-mail: raye_brahm@yahoo.com much speculation on this topic and few studies that demonstrate any real results. The lack of empirical data indicates that this violation of the rational behavior assumption in finance has not yet been explained.

To confront this problem, this paper examines this anomaly from a psychological perspective by investigating mood sources, such as weather conditions, and analyzing them as drivers of investor irrationality as it pertains to the weekend effect. It is worthwhile to note that the weekend effect is a calendar anomaly that recurs on a particular day (usually Monday) and is negatively and significantly different from other days. The weekend effect demonstrates the irrationality of investors every Monday, when investors tend to be more aggressive or violate their utility function more frequently. Hence, this paper aims to examine the drivers behind Monday irrationality by hypothesizing that weather-induced mood is the source of this irrationality. 

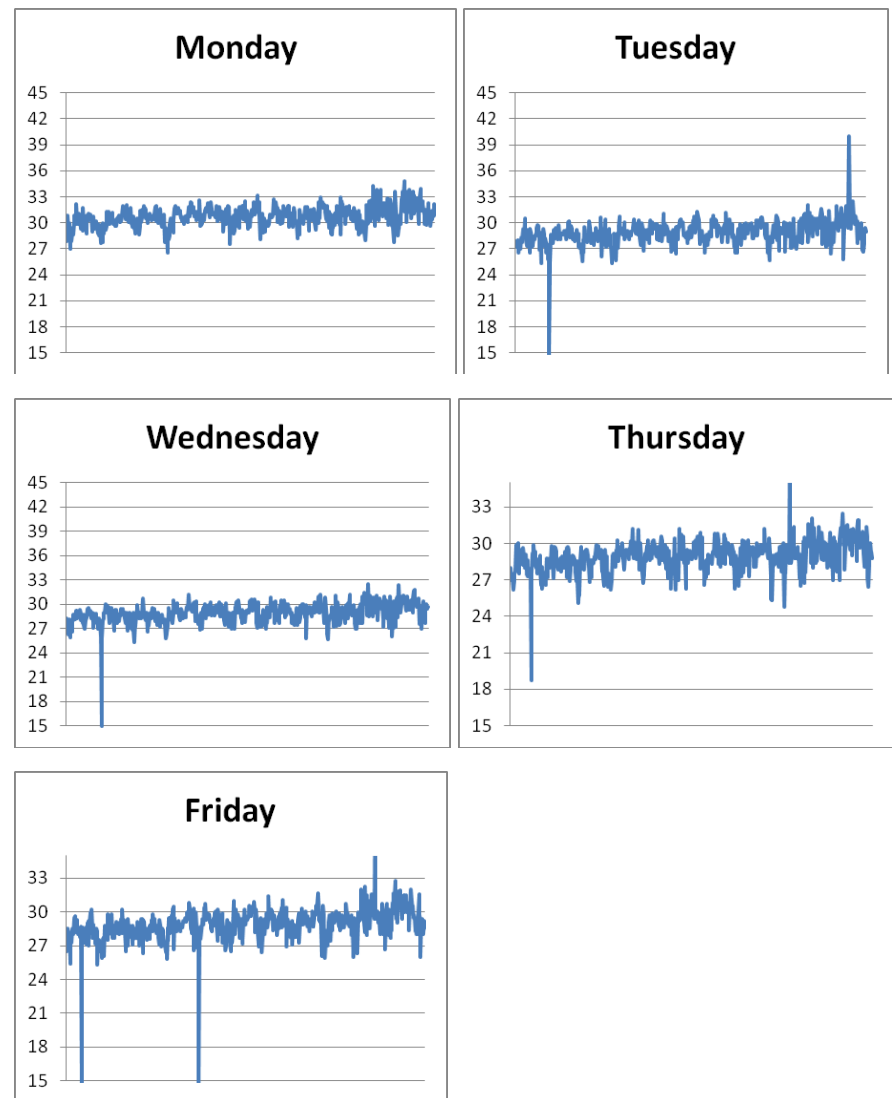

Figure 1. The Temperature in Malaysia Based on Day of the Week.

Note: The $y$-axis is the temperature in degrees Celsius; the $x$-axis is the time period (1999-2010)

Interestingly, the scientific literature shows evidence for the effect of seasonal temperature on global weather patterns (see Forster \& Solomon, 2003). Weather seasonality has been documented between Saturday and Monday, showing that it is relatively hotter on weekends compared with weekdays. This finding is in line with the Monday effect, an anomaly where investors are perceived as being irrational on Mondays. We have plotted a graph (Figure 1) to show that there is a corresponding weather anomaly. Our figure shows that the average temperature on Monday is relatively higher compared with other days of the week. The scientific literature and the figures below strengthen our presumption that Monday irrationality (the weekend effect) is caused by weather-induced mood.

To elaborate on this topic from a psychological perspective, several scholars have reported that human psychology is a factor in making biased decisions; therefore, it has been hypothesized that the irrationality present during Monday trading is caused by psychological factors such as mood disorders (see Isen et al., 1978; Hechter \& Kanazawa, 1997; Nurrunabi, 2011; Tvede, 2002). Empirical studies are also found in the economic literature regarding the relationship between mood and economic activity. One example is a study by Isen et al. (1978), which 

and Runde (1997), Pardo and Valor (2003), Hirshleifer and Shumway (2003), Tufan and Hamarat (2004), Goetzmann and Zhu (2005), Cao and Wei (2005), and Dowling and Lucey (2005), this research study was conducted in a tropical country where the temperature level is roughly constant throughout the year. Third, unlike Brahmana et al. (2012b), this research study examined the effect of firm size by investigating 10 portfolio formations ranging from small (P1) to large (P10). Fourth, unlike Dichev and Janes (2003), Goetzmann and Zhu (2005), and Brahmana et al. (2012b), whose research studies did not employ psychological theory to explain their findings, we have used Forgas' Affect Infusion Model (1985) and the Somatic Marker theory to explain our findings. Lastly, the average temperature levels in Malaysia from 3 different weather stations were employed. These differences rationalized the different positions of investors who were spread out all over Malaysia, which has been criticized in previous research studies.

This study aims to answer the following question: Does weather explain investors' Monday irrationality in Malaysia? The remainder of this paper is organized as follows: Section 2 addresses the data and methodology, Section 3 delivers the results with a brief discussion, and Section 4 provides a conclusion to this study.

\section{Data and Methodology}

\subsection{Data}

This research study used the Malaysian stock market index returns as the dependent variable. The data were retrieved from the Thomson Data Stream. Temperatures were obtained on a daily basis from the Malaysian Meteorological Office from January 1, 1999 to March 22,2010 . Our temperature calculations were similar to previous research studies (see Krämer \& Runde, 1997; Saunders, 1993) that measured the average maximum and minimum temperatures on the same day. Daily temperature data were recorded from three climate stations in Malaysia (Johor Bahru, Kuala Lumpur, and Penang). Each station reported an average temperature that was calculated from the average daily minimum and maximum temperatures between 9:00 am and 5:00 pm (trading hours). Then, we calculated the mean of these three stations' average temperature results to quantify our temperature data.

\subsection{Empirical Model}

Our baseline DOWA model was adapted from a study by French (1980) and is commonly used in the literature. This model is robust because it avoids the dummy variable trap by introducing an intercept proxy. The model is as follows:

$R_{t}=\alpha+\gamma_{1} d_{\text {Tue }, t}+\gamma_{2} d_{W e d, t}+\gamma_{3} d_{T h u, t}+\gamma_{4} d_{F r i, t}+\omega_{t}$

where $R_{t}$ is the Bursa Malaysia compounding return series; $d_{\text {Tue, },}, d_{\text {Wed }, t}, d_{\text {Thu }, t}$, and $d_{F r i, t}$ are the dummy variables for Tuesday, Wednesday, Thursday, and Friday, respectively. Traditional approaches were used to examine if the weather played a role on the weekend effect by introducing the dummy interaction model. To conclude that temperature affects Monday irrationality, we employed the following model for each day of the week, requiring that a significant coefficient occur in only the Monday model and not on other days' models. The model is given as follows:

$$
\begin{aligned}
& R_{t}=\beta_{0}+\beta_{1} D A Y+\beta_{2} T E M P+\beta_{3}(D A Y * T E M P)+ \\
& +\beta_{4} D R Y+\beta_{5} R_{t-1}+\varepsilon_{t}
\end{aligned}
$$

where $D A Y$ is the day dummy variable; TEMP is the weather in degrees Celsius; $D R Y$ is the dummy variable for the dry season, where 1 indicates the dry season and 0 indicates the rainy season; and $R$ is the stock market return. This model was tested for 5 different days of the week by changing the day dummy variable from Monday through Friday.

With regard to the robustness test, we further analyzed our data using 2 innovation models. The first innovation model was the Day-by-Day returns model. This model only tests the relationship between weather and each weekday's returns. To control the equation and increase its goodness of fit, we introduced the random walk model. This model is as follows:

$$
R_{D}=\beta_{0}+\beta_{1} T E M P_{D}+\beta_{2} D R Y+\beta_{3} R_{D-1}+\varepsilon_{t}
$$

Our last confirmation model is depicted in Model (4). This model is designed to investigate whether there is a significant relationship between extremely high and low temperature days and day-of-the-week anomalies. First, we employed Model (4) using a threshold of high temperature. We arranged the temperature data from 
Table 1. Temperature and Returns by Day

\begin{tabular}{llccc}
\hline & & Mean & Max & Min \\
\hline \multirow{2}{*}{ Monday } & Temperature & 29.96 & 41 & 24.8 \\
& Returns & -0.0530 & 1.8495 & -4.3336 \\
Tuesday & Temperature & 28.94 & 40 & 14.6 \\
& Returns & 0.1223 & 4.1039 & -3.6807 \\
Wednesday & Temperature & 28.89 & 33 & 14.9 \\
\multirow{2}{*}{ Thursday } & Returns & 0.0125 & 4.5027 & -3.1589 \\
& Temperature & 28.92 & 40 & 18.7 \\
Friday & Returns & 0.0403 & 5.7104 & -3.9179 \\
& Temperature & 28.83 & 32.5 & 12.5 \\
\hline
\end{tabular}

the lowest to the highest temperature. The highest 25\% of the temperature measurements were given a value of 1 , while the remaining measurements were given a value of 0 . This dummy variable was multiplied again by a day dummy variable to obtain the series of data that we used in Model (4). TMON, TTUES, TWED, TTHU, and TFRI are the dummy variables indicating the highest temperature measurements multiplied by the day dummy variables for Monday, Tuesday, Wednesday, Thursday, and Friday, respectively.

We repeated the same procedure with the lowest temperature measurements. We arranged the temperature data from the lowest to the highest temperature. The lowest $25 \%$ of the temperature measurements were given a value of 1 , while the remaining measurements were given a value of 0 . This dummy variable was multiplied again by a day dummy variable. The model is as follows:

$$
\begin{aligned}
& R_{t}=\gamma_{1} T M O N+\gamma_{2} T T U E+\gamma_{3} T W E D+\gamma_{4} T T H U+\gamma_{5} T F R I+ \\
& +R_{m, t-1}+\varepsilon_{t}
\end{aligned}
$$

\subsection{Procedure}

This research study conducted several procedures to investigate the relationship between temperature and Monday irrationality. First, we investigated the existence of this irrationality by replicating the procedures used by French (1980). If there was no evidence for this relationship, it would not be necessary to investigate the role of weather. Furthermore, one can argue that Monday irrationality or the Monday effect has dimin- ished. Instead of merely citing from previous studies, such as Lim and Chia (2010), to prove the existence of Monday irrationality, we have conducted an analysis to show that Monday irrationality does exist in Malaysia. Then, we examined the role of weather on Monday irrationality by introducing a dummy interaction model (Model 2) where the temperature value intersects with the day dummy variable. Lastly, we employed a dayby-day model (Model 3), which is a straightforward method in which we first pooled the data set (temperature and returns) according to the trading days (Monday to Friday) then analyzed the data separately in Model (3).

We analyzed the effect of a financial firm's size in our study. The reason for this analysis was to control the bias in decision making with regards to the size of financial firms (see Baker \& Wurgler, 2007; Blume \& Stambaugh, 1983; Palamino, 1996; Reinganum, 1983). To mimic this size effect, we constructed size-based portfolios. We ranked and sorted 10 portfolio formations from small to large market value stocks. This procedure replicates Fama-French's (1995) influential studies, where the firm's size was ranked and sorted into a $10 \%$ decile formation.

\section{Results}

\subsection{Descriptive Results}

Table 1 shows the descriptive results of our study with three important findings. First, the mean of Monday's returns was negative, indicating a weekend effect. Sec- 
Table 2. The Result of the Malaysian Stock Market DOWA

\begin{tabular}{lllllll}
\hline Period & & Monday & Tuesday & Wednesday & Thursday & Friday \\
\hline \multirow{2}{*}{$1999-2010$} & Coefficient & -0.00139 & 0.00225 & 0.001849 & 0.002161 & 0.002047 \\
& t-Statistic & -2.10892 & 2.92074 & 2.306725 & 2.277263 & 2.049677 \\
$1999-2004$ & Coefficient & -0.0014 & 0.00273 & 0.002136 & 0.00217 & 0.001929 \\
& t-Statistic & -2.91198 & 3.3461 & 2.974629 & 2.720946 & 3.032027 \\
$2004-2010$ & Coefficient & -0.00197 & 0.00276 & 0.002478 & 0.00331 & 0.004341 \\
& t-Statistic & -2.80834 & 2.78198 & 2.704061 & 2.827546 & 4.361182 \\
\hline
\end{tabular}

Note: French's (1980) regression model was performed in three sub-periods. The purpose of the sub-period segmentation was to ascertain whether the Monday effect/irrationality disappeared in certain periods or existed throughout the entire time period. The dependent variable is the market return. The independent variable is the dummy variable. Following the day-of-the-week hypothesis, the condition of Monday irrationality exists if the Monday coefficient (the intercept) is negative and statistically significant and the coefficients for other weekdays are positive and statistically significant. The model is as follows: $R_{t}=\alpha+\gamma_{1} d_{\text {Tue,t }}+\gamma_{2} d_{\text {Wed }, t}+\gamma_{3} d_{T h u, t}+\gamma_{4} d_{F r i, t}+\omega_{t}$

ond, the temperature levels on Monday had the broadest spread compared to other days, implying that the temperature levels were dispersed more widely than on other days. Lastly, Monday's temperature mean was higher than that on other days, confirming our hypothesis regarding this weather anomaly.

\subsection{Monday Irrationality (Monday Effect) in Malaysia}

This analysis was designed to prove whether Monday irrationality still exists in Malaysia or if it has disappeared. We replicated a study by French (1980) to investigate the existence of Monday irrationality. Our results showed negative returns on the Monday coefficient (the intercept). Other days, such as Tuesday, Wednesday, Thursday, and Friday, were found to be positively significant. This indicates that the returns on those days were significantly different from Monday, supporting the Monday irrationality hypothesis. This result allowed us to proceed with our study to test if weather was the explanation for the weekend effect.

\subsection{The Role of Weather on the Weekend Effect}

\subsubsection{Weather-Monday Irrationality Interaction Model}

Table 3 reports the regression estimations for Model 2; overall, the findings support our hypothesis. First, we found supporting evidence for the Monday effect from Model 2's estimates. The day dummy variable $\left(\beta_{1} D A Y\right)$ was significant if the model interacted with Monday. The coefficient was negative $(-2.4637)$ and statistically significant at the $5 \%$ level. However, when we changed the day dummy variable ( $\beta_{1} D A Y$ ) proxy to other days of the week (Tuesday through Friday), there was no evidence of a significant relationship between the day dummy variable and the market returns. This implies that Monday irrationality existed for investors in Malaysia from 1999 to 2010. We then tested the relationship between temperature and returns. We found that temperature had an effect on the stock market throughout the weekdays. Regarding the effect of the dry season, we found that there was no significant relationship between the dry season dummy variable and the market returns. This indicates that there was no difference between the dry season and the wet season in influencing investors.

The focus of this study was to investigate whether temperature plays an important role in investors' Monday irrationality. Hence, we tested this relationship by introducing an interactive term between the day dummy variable and temperature $\left(\beta_{3} D A Y^{*} T E M P\right)$. First, when the day dummy variable was Monday (i.e., Monday $=1$, others $=0$ ) and interacted with temperature, the estimate showed a negative value $(-0.0083)$ that was statistically significant. However, when we changed the day dummy variable in the interactive model (we tested the variable individually from Tuesday through Friday), the results showed no significant relationship between the interactive terms and the market returns. This result surmises that temperature is the driver of 
Table 3. Dummy Interaction Results

\begin{tabular}{|c|c|c|c|c|c|}
\hline & Day = Monday & Day = Tuesday & Day = Wednesday & Day = Thursday & Day $=$ Friday \\
\hline & 0.7812 & 1.4344 & 1.2269 & 1.2016 & 1.1061 \\
\hline \multirow[t]{3}{*}{ INTERCEPT } & [1.7579] & [3.0921] & {$[2.7023]$} & {$[2.6243]$} & [2.2988] \\
\hline & $(0.0789)$ & $(0.0020)$ & $(0.0069)$ & $(0.0087)$ & $(0.0216)$ \\
\hline & -2.4637 & 1.325 & 0.4712 & 0.3255 & -0.1383 \\
\hline \multirow[t]{3}{*}{ DAY } & {$[-2.1706]$} & [1.3334] & [0.4399] & {$[0.3127]$} & {$[-0.1501]$} \\
\hline & $(0.0300)$ & $(0.1825)$ & $(0.6600)$ & $(0.7545)$ & $(0.8807)$ \\
\hline & -0.0025 & -0.0501 & -0.0436 & -0.0423 & -0.0387 \\
\hline \multirow[t]{3}{*}{ TEMP } & {$[-1.9113]$} & {$[-3.1073]$} & {$[-2.7623]$} & {$[-2.6585]$} & {$[-2.3164]$} \\
\hline & $(0.0561)$ & (0.0019) & (0.0058) & (0.0079) & $(0.0206)$ \\
\hline & -0.0083 & -0.0429 & -0.0168 & -0.0098 & 0.0077 \\
\hline \multirow[t]{3}{*}{ DAY*TEMP } & {$[-1.9970]$} & {$[-1.2481]$} & {$[-0.4527]$} & {$[-0.2726]$} & [0.2420] \\
\hline & $(0.0459)$ & $(0.2121)$ & (0.6508) & $(0.7852)$ & (0.8088) \\
\hline & 0.0203 & 0.0157 & 0.0159 & 0.0159 & 0.0156 \\
\hline \multirow[t]{3}{*}{ DRY } & {$[0.5227]$} & {$[0.4040]$} & [0.4093] & [0.4083] & {$[0.4020]$} \\
\hline & $(0.6012)$ & $(0.6862)$ & $(0.6823)$ & $(0.6831)$ & $(0.6877)$ \\
\hline & 0.1395 & 0.1392 & 0.137 & 0.1371 & 0.1364 \\
\hline \multirow[t]{2}{*}{ RDAYMIN1 } & [7.6448] & {$[7.5922]$} & {$[7.4797]$} & [7.4893] & {$[7.4546]$} \\
\hline & $(0.0000)$ & $(0.0000)$ & $(0.0000)$ & $(0.0000)$ & $(0.0000)$ \\
\hline $\mathrm{R}^{2}$ & 0.058988 & 0.053307 & 0.051761 & 0.051958 & 0.052766 \\
\hline Adj $R^{2}$ & 0.057326 & 0.051634 & 0.050086 & 0.050283 & 0.051092 \\
\hline F-Statistic & 17.43468 & 13.93586 & 12.9909 & 13.11116 & 13.60487 \\
\hline
\end{tabular}

Note: The regressions were performed on each day's data set using White's heteroscedasticity-consistent variances ordinary least square specification. The table shows the coefficient value, [ ] is the T-statistic value, and ( ) is the p-value. The dependent variable is the market return. TEMP is the temperature. DRY is the drought season dummy variable. RDAYMIN1 is the market return of the previous day. We ran the regression five times by changing the threshold of the dummy variable from Monday through Friday. First, we ran the model with the Monday dummy variable (for the Monday model, $D A Y=1$ and others $=0$ if it is Monday). Then, the model is repeated in the same manner for the other days (e.g., for the Tuesday model, $D A Y=1$ and others $=0$ if it is Tuesday; for the Wednesday model, DAY=1, others $=0$ if it is Wednesday; for the Thursday model, $D A Y=1$, others $=0$ if it is Thursday; for the Friday model, $D A Y=1$, others $=0$ if it is Friday). The regression model is as follows: $R_{t}=\beta_{0}+\beta_{1} D A Y+\beta_{2} T E M P+\beta_{3}(D A Y * T E M P)+\beta_{4} D R Y+\beta_{5} R_{t-1}+\varepsilon_{t}$

Monday irrationality. Again, the cause of this Monday irrationality might be the higher average temperature on Monday. Note that our plot (see Figure 1) and the previous literature show temperature seasonality on Mondays; these findings are in line with Monday irrationality seen in the stock market. This result is also in line with the study by Brahmana, Hooy, and Ahmad (2012b). Furthermore, the $\mathrm{R}^{2}$ value of the Monday model is the highest compared with other days, thus confirming this relationship.
To examine the robustness of our analysis, a sizebased portfolio was constructed. Portfolio 1 was the smallest-sized portfolio, and Portfolio 10 was the largest-sized portfolio. Model 2 was then re-run to investigate the role of temperature on Monday irrationality based on portfolio size.

The results are depicted in Table 4 and are in line with our previous results shown in Table 3. Monday irrationality is again confirmed, as the Monday dummy variable $\left(\beta_{1} D A Y\right)$ contributed negatively and signifi- 
Table 4. Interaction Model: Firm Size Effect

\begin{tabular}{lllllllllll}
\hline & \multicolumn{1}{c}{$P 1$} & $P 2$ & $P 3$ & $P 4$ & $P 5$ & $P 6$ & $P 7$ & $P 8$ & $P 9$ & $P 10$ \\
\hline \multirow{2}{*}{ INTERCEPT } & 0.0461 & 0.0532 & 0.2571 & 0.2107 & 0.0345 & 0.7026 & 0.2591 & 0.0274 & 0.0678 & 1.1181 \\
& {$[0.0272]$} & {$[0.9138]$} & {$[-0.665]$} & {$[0.959343]$} & {$[0.3446]$} & {$[1.0696]$} & {$[0.9041]$} & {$[1.4261]$} & {$[1.5622]$} & {$[0.7634]$} \\
& $(0.9783)$ & $(0.3609)$ & $(0.5056)$ & $(0.3375)$ & $(0.7304)$ & $(0.2849)$ & $(0.3660)$ & $(0.1540)$ & $(0.1184)$ & $(0.4453)$ \\
DAY & -0.8791 & -0.6129 & -0.6824 & -0.7275 & -0.1078 & -0.3522 & -0.4695 & -0.6137 & -0.2436 & -0.2389 \\
& {$[-3.1839]$} & {$[-2.1407]$} & {$[-3.840]$} & {$[-3.73717]$} & {$[-6.6255]$} & {$[-3.2890]$} & {$[-2.0499]$} & {$[-3.0123]$} & {$[-2.9595]$} & {$[-2.6442]$} \\
& $(0.0015)$ & $(0.0324)$ & $(0.0001)$ & $(0.0002)$ & $(0.0000)$ & $(0.0010)$ & $(0.0405)$ & $(0.0026)$ & $(0.0031)$ & $(0.0082)$ \\
TEMP & -0.0729 & -0.0934 & -0.0051 & -0.0711 & -0.0479 & -0.2107 & -0.0614 & -0.053 & -0.0901 & -0.0704 \\
& {$[2.0739]$} & {$[-2.4745]$} & {$[-2.198]$} & {$[-2.9659]$} & {$[-2.4196]$} & {$[-2.5599]$} & {$[-2.6974]$} & {$[-1.8982]$} & {$[-1.3997]$} & {$[-0.7866]$} \\
& $(0.0382)$ & $(0.0134)$ & $(0.0280)$ & $(0.0030)$ & $(0.0156)$ & $(0.0105)$ & $(0.0070)$ & $(0.0578)$ & $(0.1617)$ & $(0.4316)$ \\
DAY*TEMP & 0.3059 & 0.2085 & 0.2341 & 0.2525 & 0.3708 & 1.2802 & 0.1553 & 0.2192 & 0.0874 & 0.0831 \\
& {$[3.180641]$} & {$[2.0904]$} & {$[3.8771]$} & {$[3.723868]$} & {$[6.5459]$} & {$[3.4321]$} & {$[1.9463]$} & {$[3.0912]$} & {$[1.4410]$} & {$[0.7855]$} \\
& $(0.0015)$ & $(0.0367)$ & $(0.0001)$ & $(0.0002)$ & $(0.0000)$ & $(0.0006)$ & $(0.0517)$ & $(0.0020)$ & $(0.1497)$ & $(0.4322)$ \\
DRY & 0.3653 & 0.3169 & 0.2028 & 0.0047 & 0.0963 & 0.0844 & 0.0126 & 0.3099 & 0.1466 & 0.3009 \\
& {$[1.6108]$} & {$[1.3507]$} & {$[1.389]$} & {$[0.02949]$} & {$[1.4416]$} & {$[1.2603]$} & {$[0.0883]$} & {$[1.2424]$} & {$[0.7789]$} & {$[1.8047]$} \\
& $(0.1073)$ & $(0.1769)$ & $(0.1648)$ & $(0.9765)$ & $(0.1495)$ & $(0.2077)$ & $(0.9297)$ & $(0.2142)$ & $(0.4361)$ & $(0.0712)$ \\
Adj. R2 & 0.0251 & 0.01507 & 0.0386 & 0.03741 & 0.0147 & 0.0487 & 0.0234 & 0.026 & 0.0251 & 0.051 \\
F-Statistic & 2.8369 & 2.1005 & 3.8395 & 3.7459 & 11.9289 & 4.5764 & 2.7139 & 2.873 & 0.9818 & 0.625 \\
\hline & 0.2069 & 0.3055 & 0.7208 & 0.0704 & -1.1615 & 0.8989 & 0.201 & 0.1252 & -0.1715 & -0.1051 \\
RDAYMIN1 & {$[3.1297]$} & {$[1.9663]$} & {$[4.122]$} & {$[2.644176]$} & {$[-2.6906]$} & {$[4.5872]$} & {$[6.3813]$} & {$[4.5582]$} & {$[-2.3848]$} & {$[-1.6770]$} \\
& $(0.0018)$ & $(0.0494)$ & $(0.0000)$ & $(0.0082)$ & $(0.0072)$ & $(0.0000)$ & $(0.0000)$ & $(0.0000)$ & $(0.0172)$ & $(0.0937)$ \\
\hline
\end{tabular}

Note: We performed a robustness test to examine whether irrationality had a different effect in firms of different sizes. We formed 10 size-based portfolios according to their market capitalization (see Fama and French, 1992 for details). Then, we proceeded by taking the return of each portfolio and treating it as the dependent variable. The regressions were performed using White's heteroscedasticity-consistent variances ordinary least square specification. We reran Model 2, but only with the Monday model (DAY=1 and others=0 if it is Monday). TEMP is the temperature. DRY is the drought season dummy variable. RDAYMIN1 is the Friday returns. The model is as follows: $R_{t}=\beta_{0}+\beta_{1} D A Y+\beta_{2} T E M P+\beta_{3}\left(D A Y^{*} T E M P\right)+\beta_{4} D R Y+\beta_{5} R_{t-1}+\varepsilon_{t}$. The table shows the coefficient value, [ ] is the T-statistic value, and ( ) is the p-value.

cantly to portfolio returns. This implies that Monday irrationality does exist regardless of the size of the portfolio. The temperature $\left(\beta_{2}\right.$ TEMP) contributed negatively and significantly only in small-sized and medium-sized portfolios, but not in large-sized portfolios. This finding is in line with the estimates of the $\left(\beta_{3} D A Y^{*} T E M P\right)$ model, which showed no significant role of temperature interactions on Mondays in largesized portfolios. Lastly, Table 4 shows that the presence of the dry or wet season had no effect on the influence of temperature on investors. Therefore, we surmise that temperature is the driver of Monday irrationality and can be used to make predictions about small and medium-sized firms but not large-sized firms.

\subsubsection{Day-by-Day Model}

To make our research more robust, we re-investigated the role of temperature on Monday irrationality by using a different approach. Instead of using only the interactive terms, we employed a day-by-day model, which is formulated in Model 3. A day-by-day regression model (Model 3) indicates that we extracted each day's returns, including temperature, as one unique data set. For instance, we extracted only Monday's returns and Mon- 
Table 5. Day-by-Day Model Results

\begin{tabular}{|c|c|c|c|c|c|}
\hline & Day = Monday & Day = Tuesday & Day = Wednesday & Day = Thursday & Day $=$ Friday \\
\hline & 0.0133 & 0.0023 & 0.0003 & 0.0005 & 0.0008 \\
\hline \multirow[t]{3}{*}{ Intercept } & {$[0.0122]$} & {$[0.00274]$} & {$[0.0320]$} & {$[0.0523]$} & [0.0935] \\
\hline & $(0.9031)$ & (0.9978) & $(0.9745)$ & (0.9583) & $(0.9255)$ \\
\hline & -0.0041 & 0.0016 & -0.0007 & -0.0028 & -0.0032 \\
\hline \multirow[t]{3}{*}{ TEMP } & {$[-3.8577]$} & [1.3597] & {$[-0.7923]$} & {$[-0.7945]$} & {$[-0.6537]$} \\
\hline & $(0.0001)$ & $(0.1528)$ & $(0.4283)$ & $(0.4269)$ & $(0.5134)$ \\
\hline & 0.0724 & 0.0442 & 0.0815 & 0.0501 & 0.0144 \\
\hline \multirow[t]{3}{*}{ DRY } & [1.6225] & [1.2859] & [2.1814] & [1.4084] & [0.3957] \\
\hline & $(0.1048)$ & $(0.1986)$ & $(0.0292)$ & $(0.1591)$ & $(0.6923)$ \\
\hline & 0.3437 & -0.0841 & 0.1379 & 0.1503 & 0.2856 \\
\hline \multirow[t]{2}{*}{ RDAYMIN1 } & [15.7930] & {$[-6.1370]$} & [6.8908] & [8.6084] & [15.2711] \\
\hline & $(0.0000)$ & $(0.0000)$ & $(0.0000)$ & $(0.0000)$ & $(0.0000)$ \\
\hline R2 & 0.0957 & 0.0186 & 0.01834 & 0.0286 & 0.0819 \\
\hline Adj. R2 & 0.0948 & 0.01762 & 0.0173 & 0.0276 & 0.081 \\
\hline F-Statistic & 91.3105 & 18.4844 & 18.1942 & 28.6938 & 86.8885 \\
\hline
\end{tabular}

Note: The regressions were performed on each day's data set using White's heteroscedasticity-consistent variances ordinary least square specification. The table shows the coefficient value, [ ] is the T-statistic value, and ( ) is the p-value. First, we separated the data according to the day of the week. For the Monday model, we used Monday's temperature and Friday's returns. For the Tuesday Model, we used Tuesday's temperature and Monday's returns. For the Wednesday model, we used Wednesday's temperature and Tuesday's returns. For the Thursday model, we used Thursday's temperature and Wednesday's returns. For the Friday model, we used Friday's temperature and Thursday's returns. We ran the regression model five times by changing the data set according to the days of the week. The dependent variable is the market return. TEMP is the temperature. DRY is the drought season dummy. RDAYMIN1 is the Friday returns. The model is as follows: $R_{D}=\beta_{0}+\beta_{1} T E M P_{D}+\beta_{2} D R Y+\beta_{3} R_{D-1}+\varepsilon_{t}$

day's temperatures and then ran it through Model (3). This is what we termed the Monday model. We repeated the same procedure with the other data sets, from Tuesday through Friday. For example, we extracted Wednesday's returns and Wednesday's temperatures, named it the Wednesday model, and then ran it through Model (3). To establish a rigorous conclusion, this robustness test had to meet the following two conditions: (1) the temperature had to significantly impact returns; and (2) the result must only be documented for the Monday data set, not for the other data sets.

Tables 5 and 6 show the results of the day-by-day mod$\mathrm{el}$ in the market and portfolio formation modes. The average of the $\mathrm{R}^{2}$ value is $9 \%$, which is acceptable for a study that includes a dummy-based model. Furthermore, the F statistic of the model is accepted at the $1 \%$ significance level, implying that the model cannot be rejected.
Table 5 reports the estimates of Model 3 where the market returns are the dependent variable. These results confirm the interactive model (Model 2) results, where the temperatures on Mondays contributed negatively and significantly to market returns on Mondays at a $1 \%$ significance level. Meanwhile, there was no significant relationship between the temperatures of other weekdays on the market returns of other weekdays, even at the $10 \%$ significance level. The coefficient value for Monday was negative (-0.0041). This indicates that if the temperature increases by 1 Celsius unit, market returns might be lowered by $0.4 \%$. Additionally, our results showed that the dry season dummy variable had no effect on the market returns.

These results imply that psychological bias (caused by temperature) has a significant relationship with market performance. The negative coefficient indicates 
Table 6. Firm Size Effect: Day-by-Day Model

\begin{tabular}{lcccccccccc}
\hline & $P 1$ & $P 2$ & $P 3$ & $P 4$ & $P 5$ & $P 6$ & $P 7$ & $P 8$ & $P 9$ & $P 10$ \\
\hline \multirow{4}{*}{ Intercept } & 0.9834 & 0.015 & 0.005 & 2.2403 & 2.2452 & 0.5243 & 0.029 & 1.8388 & 1.3517 & 0.6183 \\
& {$[2.0258]$} & {$[0.0719]$} & {$[0.106]$} & {$[1.9594]$} & {$[1.6684]$} & {$[1.4587]$} & {$[0.0735]$} & {$[0.7986]$} & {$[0.6208]$} & {$[0.3532]$} \\
& $(0.0429)$ & $(0.9427)$ & $(0.915)$ & $(0.0502)$ & $(0.0954)$ & $(0.1448)$ & $(0.9414)$ & $(0.4246)$ & $(0.5348)$ & $(0.7239)$ \\
& -0.0014 & -0.0047 & -0.0009 & -0.0812 & -0.0792 & -0.3072 & -0.0051 & -0.0635 & -0.0447 & -0.0216 \\
TEMP & {$[-1.9999]$} & {$[-2.6863]$} & {$[-2.085]$} & {$[-2.0524]$} & {$[-1.7001]$} & {$[-1.5197]$} & {$[-1.3277]$} & {$[-0.7976]$} & {$[-0.5939]$} & {$[-0.3571]$} \\
& $(0.0456)$ & $(0.0073)$ & $(0.037)$ & $(0.0402)$ & $(0.0892)$ & $(0.1287)$ & $(0.1844)$ & $(0.4252)$ & $(0.5526)$ & $(0.7210)$ \\
& 0.348 & 1.6333 & 0.06 & 0.386 & 0.0822 & 0.5468 & 0.182 & 0.3641 & 0.4567 & 0.4114 \\
DRY & {$[1.0261]$} & {$[1.9076]$} & {$[0.332]$} & {$[2.0153]$} & {$[0.3648]$} & {$[0.5585]$} & {$[1.1340]$} & {$[0.9440]$} & {$[1.2537]$} & {$[1.4030]$} \\
& $(0.3049)$ & $(0.0565)$ & $(0.740)$ & $(0.0440)$ & $(0.7153)$ & $(0.5765)$ & $(0.2569)$ & $(0.3453)$ & $(0.2100)$ & $(0.1607)$ \\
& 1.4221 & 0.1818 & 0.322 & 0.7088 & 1.1636 & 0.3888 & 0.2922 & 1.1258 & 1.4919 & 1.2351 \\
RDAYMIN1 & {$[15.7155]$} & {$[0.9982]$} & {$[8.369]$} & {$[13.8575]$} & {$[19.3283]$} & {$[1.4870]$} & {$[8.4417]$} & {$[10.9280]$} & {$[15.2588]$} & {$[15.7713]$} \\
& $(0.0000)$ & $(0.3183)$ & $(0.000)$ & $(0.0000)$ & $(0.0000)$ & $(0.1371)$ & $(0.0000)$ & $(0.0000)$ & $(0.0000)$ & $(0.0000)$ \\
\hline R2 & 0.0796 & 0.0289 & 0.0256 & 0.0639 & 0.1144 & 0.0016 & 0.0250 & 0.0396 & 0.0744 & 0.0788 \\
Adj. R2 & 0.0786 & 0.0186 & 0.0246 & 0.0629 & 0.1135 & 0.0006 & 0.0240 & 0.0386 & 0.0735 & 0.0778 \\
F-Statistic & 84.042 & 28.8197 & 25.6146 & 66.4396 & 125.8266 & 29.5780 & 24.5773 & 40.1405 & 78.0580 & 83.2962 \\
\hline
\end{tabular}

Note: We performed a robustness test to examine whether irrationality has a different effect in firms of different sizes. We formed 10 size-based portfolios according to their market capitalization (see Fama and French, 1992 for details). Then, we proceeded by taking the return of each portfolio and treating it as the dependent variable. Note that we considered only the Monday return from each portfolio. The regressions were performed using White's heteroscedasticity-consistent variances ordinary least square specification. We reran Model 3 with only the Monday model (DAY=1 and others $=0$ if it is Monday). TEMP is the temperature on Mondays. DRY is the drought season dummy. RDAYMIN1 is the Friday returns. The model is as follows: $R_{D}=\beta_{0}+\beta_{1} T E M P_{D}+\beta_{2} D R Y+\beta_{3} R_{D-1}+\varepsilon_{t}$. The table shows the coefficient value, [ ] is the T-statistic value, and ( ) is the $\mathrm{p}$-value.

that when the temperature is higher, the market tends to be bearish. This could be due to increased aggressiveness of investors, causing them to violate their utility function and act irrationally. As a consequence, investors trade following their mood (hedonic utility) instead of their utility function. This is consistent with the studies by Saunders (1993) and Brahmana et al. (2012b), who demonstrated evidence for the relationship between the weather and stock market.

Again, we controlled for the size effect by constructing size-based portfolios and running them through Model 3. Table 6 shows the estimations with portfolio formation returns as the dependent variable. The results were similar to the market return results (Table 5), where there was a temperature effect on Monday irrationality. The role of temperature on Monday irrationality was seen in Portfolios 1 through 5 , indicating that the effect of Monday irrational- ity was seen only in small-sized and medium-sized firms. Large-sized portfolios were not affected by this weather irrationality.

The magnitude of this effect was quite high, as the coefficient values ranged from -0.0014 to -0.0792 . This implies that higher temperatures indicated lower returns on Mondays. The dry or wet season was not important, as it was not significant at either the $1 \%$ or $5 \%$ significance levels in Table 6. This indicates that there was no difference in the temperature effect between the dry and wet seasons.

\subsubsection{Extreme Weather}

Our hypothesis rests on the assumption that because temperatures on Monday are higher, on average, compared to other days, Monday irrationality exists. To strengthen this hypothesis, we conducted another robustness test that examines extreme weather. We built 
Table 7. The Relationship between Extremely High Temperature Conditions and the Day-of-The-Week Anomaly

\begin{tabular}{lcc}
\hline Variable & $\begin{array}{c}\text { Coefficient of Extremely High } \\
\text { Temperature }\end{array}$ & $\begin{array}{c}\text { Coefficient of Extremely Low } \\
\text { Temperature }\end{array}$ \\
\hline TMON & $-0.0927^{* *}$ & 0.0564 \\
TTUES & 0.0448 & 0.0117 \\
TWED & 0.0256 & $0.0116^{*}$ \\
TTHU & 0.0122 & $0.0135^{*}$ \\
TFRI & 0.0303 & $0.0121^{*}$ \\
RMIN1 & $0.1427^{* * *}$ & $0.1363^{* * *}$ \\
\hline
\end{tabular}

Note: We examined the role of extreme temperature by adopting French's (1980) model. The dependent variable is the market return. The independent variable is the temperature according to day of the week. TMON is Monday's temperature, TTUES is Tuesday's temperature, TWED is Wednesday's temperature, TTHU is Thursday's temperature, TFRI is Friday's temperature, and RMIN1 is the returns of previous day. The model is as follows: $R_{t}=\gamma_{1} T M O N+\gamma_{2} T T U E+\gamma_{3} T W E D+\gamma_{4} T T H U+\gamma_{5} T F R I+R_{m, t-1}+\varepsilon_{t} \cdot\left(^{*}\right)\left(*^{*}\right)\left(*^{* *}\right)$ denotes $(10 \%)(5 \%)(1 \%)$ statistical significance, respectively

two other models (model 4 and model 5) by treating extreme temperatures as dummy variables. This was performed by considering the highest and lowest $10 \%$ of temperature measurements as the extreme values. On the dates that had extreme temperatures, we assigned a dummy value of 1 . This method follows the previous report of Brahmana et al., (2012b), who examined the Indonesian stock market.

Table 7 shows the estimates of Model 4. If the threshold was set at the high temperature measurements, our findings showed that only extreme temperatures on Monday had a significant relationship with market returns. The coefficient was -0.0927 , implying that the market returns might decrease by 0.0927 if a high temperature occurred on Monday. Interestingly, high temperature extremes on other days of the week did not significantly contribute to market returns. Considering that temperatures on Monday are higher, on average, than temperatures on other days of the week, these findings confirm our hypothesis that that extreme weather conditions on Monday are the source of this day-of-the-week anomaly. Mood changes generate random decision making processes that can cause anomalies in the market. These results also confirm the similar findings of Forster and Solomon (2003) regarding weather calendar anomalies. Our findings also strengthen the correlation between weather and the week effect reported by
Jaffe and Westerfield (1985); both studies enrich the behavioral finance literature by surmising that there is an effect of weather-induced mood on day-of-theweek anomalies.

We continued to test our hypothesis by changing the threshold from extremely high temperatures to extremely low temperatures. If higher average temperatures on Monday caused Monday irrationality, perhaps extremely low temperatures did not have an effect on market returns.

Table 7 shows that extremely low temperatures influenced investor irrationality only on some weekdays: Wednesday, Thursday, and Friday. Furthermore, these low temperatures influenced the returns at the $10 \%$ significance level, a result generally considered to be not significant. In addition, there was no effect on market returns of extremely low temperatures on Monday and Tuesday.

The most convincing explanation for these findings is the environmental psychological approach, a study regarding the role of the environment on human behavior. For instance, McAndrew (1993) noted that a lack of sunlight makes people melancholic and upset. Bell et al., (2003) reported a summer effect, where people feel impatient or angry when the temperature is greater than $84^{\circ} \mathrm{F}$. These studies also showed that, unlike hot temperatures, cold temperatures make people upset. 


\section{Conclusion}

Rational behavior, which is the main assumption in conventional finance, has been extensively challenged by behavioral scholars. The inability of conventional finance to explain the existence of Monday irrationality (the Monday effect) is evidence for a failure of the rational behavior assumption. The scholars in behavioral economics have rejected this assumption by introducing the concept of hedonic utility, where the psychology of investors plays an important role in decision making.

This paper examines the relationship between weather conditions and investors' Monday irrationality. The literature has shown that weather conditions (e.g., temperature) can influence investors' moods during trading. We extended this research further by elaborating upon psychology and finance after examining several interesting facts: (1) there is Monday irrationality present in Malaysian stock markets; (2) there is also weather seasonality, which has been documented by Forster and Solomon (2003); and (3) our data analysis shows that the temperature on Mondays is higher, on average, than the temperature on other days of the week. We used these facts as our starting point to further investigate if weather, as a source of mood disorders, has an effect on investor irrationality.

Several of our findings support our hypothesis. First, our results showed that the Monday dummy variable had a significant effect on the model; however, other weekday dummy variables did not. This finding strengthened the evidence for Monday irrationality in the Malaysian stock market, which is in line with prior research studies (see Kok and Wong, 2004; Lim and Chia, 2010). Second, temperature was found to be significant on weekdays, which is in line with prior research studies, such as those published by Saunders (1993), Hirshleifer and Shumway (2003), Pardo and Valor (2003), and Dowling and Lucey (2008). This indicates that temperature had an effect throughout the week, which is representative of the tropical weather patterns in Malaysia. The dry season dummy variable indicated that there was no difference between the dry and wet seasons regarding the behavior of investors. Unlike countries that have four seasons, Malaysia does not have seasonal affective disorders, which occur due to changing seasons.

Lastly, our model has documented the role of weather on the Monday effect by using two models: the interactive model and the day-by-day model. Our findings are concordant with the literature in psychology. For example, Howarth and Hoffman (1984) stated that weather can affect the emotional state of humans. Basu and Samet (2002), Kovat and Ebi (2006), and Hansen et al. (2008) found that high temperatures can affect mental health. This is why a negative relationship was found between temperatures and returns on Mondays (i.e., the higher the temperature, the lower the returns). In the context of a tropical country, as well as in Malaysia, the literature in psychology also documents the role of temperature on human behavior. For instance, Pakiam and Lim (1984) found a relationship between weather and crime rates. Jain et al. (1992) documented a link between climate and admissions for mood disorder (e.g., mania). Lee, Tsai and Lin (2007) found that a seasonality variation in bipolar disorder does exist and is associated with climate. Furthermore, Van de Vliert et al. (1999) analyzed 136 countries for a relationship between temperature and domestic political violence and found that countries with a mean daytime temperature of approximately 24 degrees Celsius (tropical weather) tend to suffer from more violent political actions compared with colder or warmer countries. This may be due to the level of aggressiveness being different due to warmer temperatures. These findings show that investors may be influenced by temperature. Investors are mentally obstructed by high temperatures, possibly resulting in irrationality.

Because this research study aims to explain this irrationality, one can argue that there is a different level of attention with regards to the size effect (see Blume and Stambaugh, 1983; Meneu \& Pardo, 2004; Reinganum, 1983; Ritter, 1988). Hence, we formed size-based portfolios and repeated our models to address this issue. Our results showed that there is size interference on the role of temperature. Small-sized and mediumsized portfolios were found to be affected by temperature; however, large-sized portfolios were not affected. This indicates that small and medium cap formations are influenced by weather on Mondays, but large cap formations are not. This is consistent with the study by Reinganum (1983), who found that small firms experienced seasonality compared to large firms (the size effect anomaly). Blume and Stambaugh (1983) concluded the same result, where there was a small 



\section{References}

Abraham, A., \& Ikenberry, D. L. (1994). The Individual Investor and the Weekend Effect. The Journal of Financial and Quantitative Analysis, 29 (2), 263 -277.

Baker, M., \& Wurgler, J. (2007). Investor Sentiment in the Stock Market. Journal of Economic Perspectives, 21 (2), 129-152.

Basu, R., \& Samet, J. M. 2002. Relation between Elevated Ambient Temperature and Mortality: A Review of the Epidemiologic Evidence. Epidemiologic Reviews, 24 (2), 190-202.

Bell, P. A., Greene, T. C., Fisher, J. D., \& Baum, A. (2001). Environmental psychology (5th ed.). Fort Worth, TX: Harcourt College Publishers.

Blume, M. E., \& Stambaugh, R. F. (1983). Biases in computed returns: An application to the size effect. Journal of Financial Economics, 12 (3), 387-404.

Brahmana, R., Hooy, C. W., \& Ahmad, Z. (2012a). Psychological Factors on Irrational Financial Decision Making: Case of Day-of-the Week Anomaly. Humanomics: The International Journal of Systems and Ethics, 28 (4), 236-257.

Brahmana, R., Hooy, C. W., \& Ahmad, Z. (2012b). Weather, investor irrationality and day-of-theweek anomaly: case of Indonesia. Journal of Bioeconomics, 14 (2), 129-146.

Cao, M., \& Wei, J. (2005). Stock market returns: A note on temperature anomaly. Journal of Banking \& Finance, 29 (12), 1559-1573.

Chin, S. K., \& Abdullah, N. A. H. (2013). Announcement Effect of Corporate Bond Issuance and Its Determinants. Contemporary Economics, 7 (1), 5-18.

Dichev, I. D., \& Janes, T. D. (2003). Lunar cycle effects in stock returns - Some preliminary Irish evidence. Journal of Private Equity, 6 (4), 8 -29.

Dowling, M. M., \& Lucey, B. M. (2005). Weather, Biorhytms, Beliefs, and Stock Returns. International Review of Financial Analysis, 14 (3), 337-355.

Ellis, A. (1958). Rational psychotherapy. Journal of General Psychology, 59, 35-49. New York, NY: Institute for Rational-Emotive Therapy (Original work published ROK).

Fama, E. F., \& French, K. R. (1995). Size and Book-toMarket Factors in Earnings and Returns. Journal of Finance, 50 (1), 131-155.
Forgas, J. P. (1995). Mood and Judgment: The Affect Intrusion Model (AIM). Psychological Bulletin, 117 (1), 39-66.

Forster, P. M. F., \& Solomon, S. (2003). Observations of a "Weekend Effect" in Diurnal Temperature Range. Proceedings of the National Academy of Sciences of the United States of America, 100 (20), 11225-11230.

French, K.R. (1980). Stock Returns and The Weekend Effect. Journal of Financial Economics, 8 (1), 55-69.

Goetzmann, W. N., \& Zhu, N. (2005). Rain or Shine: Where is the Weather Effect? European Financial Management, 11 (5), 559-578.

Hansen, A., Bi, P., Nitschke, M., Ryan., P., Pisaniello, D., \& Tucker, G. (2008). The Effect of Heat Waves on Mental Health in a Temperate Australian City. Environmental Health Perspective, 116 (10), 1369-1375.

Hechter, M., \& Kanazawa, S. (1997). Sociological rational choice theory. Annual Review of Sociology, 23, 191214 .

Hirshleifer, D., \& Shumway, T. (2003). Good Day Sunshine: Stock Returns and the Weather. The Journal of Finance, 58 (3), 1009-1032.

Howarth, E., \& Hoffman, M. S. (1984). A Multidimensional Approach to the Relationship between Mood and Weather. British Journal of Psychology, 75 (1), 15-23.

Isen, A., Shalker, T. E., Clark, M., \& Karp, L. (1978). Affect, accessibility of material in memory and behavior: A cognitive loop? Journal of Personality and Social Psychology, 36 (1), 1-12.

Jaffe, J., \& Westerfield, R. (1985) The Week-End Effect in Common Stock Returns: The International Evidence. The Journal of Finance, 40 (2), 433-454.

Jain, S., Kaliaperumal, V. G., Chatterji, S., Rao, S., \& Murthy, R. S. (1992). Climate and admissions for mania in the tropics. Journal of affective disorders, 26 (4), 247-250.

Kahneman, D., \& Tversky. A. (1979). Prospect theory: an analysis of decision under risk. Econometrica, 47 (2), 263-291.

Kamstra, M. J., Kramer, L. A., \& Levi, M. D. (2000). Winter blues: Seasonal Affective Disorder (SAD), the January effect, and stock market returns (Working Paper Economics No. 872). Faculty of Commerce, University of British Columbia. 
Kok, K. L., \& Wong, Y. C. (2004). Seasonal anomalies of stocks in ASEAN equity markets. Sunway College Journal, 1, 1-11.

Kovats, R. S \& Kristie, L. E. (2006). Heatwaves and Public Health in Europe. The European Journal of Public Health, 16 (6), 592-599.

Krämer, W., \& Runde, R. (1997). Stocks and the Weather: An Exercise in Data Mining or Yet Another Capital Market Anomaly?. Empirical Economics, 22, 637-641.

Kudryavtsev, A., Cohen, G., \& Hon-Snir, S. (2013). Rational or Intuitive: Are Behavioral Biases Correlated Across Stock Market Investors? Contemporary Economics, 7 (2), 33-53.

Lee, H. C., Tsai, S. Y., \& Lin, H. C. (2007). Seasonal variations in bipolar disorder admissions and the association with climate: a populationbased study. Journal of affective disorders, 97 (1), 61-69.

Lim, S. Y., \& Chia, R. C. J. (2010). Stock market calendar anomalies: Evidence from ASEAN-5 stock markets. Economics Bulletin, 30 (2), 996-1005.

McAndrew, F. T. (1993). Environmental Psychology. Pacific Grove, CA: Brooks/Cole.

Meneu, V., \& Pardo, A. (2004). Pre-holiday effect, large trades and small investor behaviour. Journal of Empirical Finance, 11 (2), 231-246.

Nurunnabi, M. (2012). Testing weak-form efficiency of emerging economies: a critical review of literature. Journal of Business, Economics and Management, 13 (1) 167-188.

Pakiam, J. E., \& Lim, J. (1984). Crime and weather in Singapore. International Journal of Comparative and Applied Criminal Justice, 8 (1-2), 209-220.

Palomino, F. (1996). Noise trading in small markets. The Journal of Finance, 51 (4), 1537-1550.

Pardo, Angel, \& Valor, E. (2003). Spanish Stock Returns: Where is the Weather Effect? European Financial Management, 9 (1), 117-126.

Reinganum, M. R. (1983). The anomalous stock market behavior of small firms in January: Empirical tests for tax-loss selling effects. Journal of Financial Economics, 12 (1), 89-104.

Ritter, J. R. (1988). The buying and selling behavior of individual investors at the turn of the year. The Journal of Finance, 43 (3), 701-717.

Saunders, E. M. (1993). Stock Prices and Wall Street
Weather. The American Economic Review, 83 (5), 1337-1345.

Schwarz, N., \& Clore, G. L. (1983). Mood, Misattribution, and Judgment of Well-being: Informative and Directive Function of Affective States. Journal of Personality and Social Psychology, 45 (3), 513-523.

Tufan, E., \& Hamarat, B. (2004). Do Cloudy Days Affect Stock Exchange Returns: Evidence from Istanbul Stock Exchange. Journal of Naval Science and Engineering, 2 (1), 117-126.

Tvede, L. (2002). The Psychology of Finance: Understanding the Behavioral Dynamics of Markets. Revised Edition. New York, NY: John Wiley and Sons.

Van de Vliert, E., Schwartz, S. H., Huismans, S. E., Hofstede, G., \& Daan, S. (1999). Temperature, Cultural Masculinity, and Domestic Political Violence A Cross-National Study. Journal of Cross-Cultural Psychology, 30 (3), 291-314.

Yahyazadehfar, M., Abounoori, E., \& Shababi, H. (2006). Days-of-Week Effect on Tehran Stock Exchange Returns: An Empirical Analysis. Iranian Economic Review, 11 (2), 149-164.

\section{Endnotes}

1. There are several fund managers who run their asset management using the-so-called superstitious fund. Please refer to the news at http://www. bbc.com/future/story/20120731-bulls-bears-andblack-cats and http://www.thejakartapost.com/ news/2011/08/08/market-forecast-buy-cloudy-sellsunny.html 
